[1]

\title{
KONTEKS ORGANISASI, TEKNOLOGI INFORMASI DAN KAPABILITAS KNOWLEDGE SHARING PEGAWAI DI PT PLN (PERSERO) AREA PALEMBANG
}

\author{
Supardi $^{1(a)}$ \\ ${ }^{1}$ Jurusan Ilmu Pemerintahan, Universitas Tamansiswa Palembang \\ ${ }^{a)}$ Pardi297474@gmail.com
}

\begin{tabular}{l}
\multicolumn{1}{c}{ INFORMASI } \\
ARTIKEL \\
\hline \\
Article History: \\
Dikirim: \\
29-07-2021 \\
Selesai Revisi: \\
15-09-2021 \\
Diterbitkan Online: \\
30-09-2021 \\
\hline
\end{tabular}

\section{Kata Kunci:}

Budaya Organisasi, Struktur

Organisasi, Teknologi

Informasi, Kapabilitas

Knowledge Sharing
Perubahan pesat pada era informasi secara tidak langsung menghendaki adanya reformasi pada sektor publik. Sektor publik harus terus berbenah, salah satunya melalui penciptakan inovasi. Inovasi dalam sektor publik dilakukan melalui penciptaan ide yang tidak terlepas dari proses berbagi pengetahuan (knowledge sharing). Berbagi pengetahuan penting bagi organisasi mengingat hakikat pengetahuan yang sifatnya komplementari dan tidak ada satupun individu yang menguasai semua bidang pengetahuan. Sayangnya, belum banyak instansi publik yang menerapkan manajemen pengetahuan dengan baik melalui pemanfaatan teknologi informasi dengan mempertimbangkan budaya organisasi dan tipe struktur organisasi. Tujuan penelitian ini adalah untuk menguji bagaimana pengaruh internalisasi budaya organisasi dan struktur organisasi fungsional terhadap kapabilitas knowledge sharing di PT. PLN (Persero) Area Palembang dengan memasukkan faktor teknologi informasi sebagai variabel intervening. Metode yang digunakan dalam penelitian ini adalah metode kuantitatif dengan menggunakan kuesioner sebagai data primer. Sampel yang digunakan dalam penelitian ini yaitu sampel sensus sehingga seluruh populasi digunakan sebagai responden penelitian. Hasil penelitian menunjukkan bahwa penggunaan teknologi informasi memediasi pengaruh internalisasi budaya organisasi terhadap kapabilitas knowledge sharing tetapi tidak memediasi pengaruh struktur organisasi fungsional terhadap kapabilitas knowledge sharing. Berdasarkan temuan tersebut, saran yang diberikan peneliti yaitu: memaksimalkan pemanfaatan teknologi informasi dengan tetap menjaga budaya dan iklim organisasi yang kondusif untuk peningkatan kapabilitas knowledge sharing.

\section{Keywords:}

Organizational Culture, Organizational Structure, Information Technology, Knowledge Sharing Capability

Corresponding Author: Pardi297474@gmail.com

DOI:
Rapid changes in the information age indirectly require reforms in the public sector. The public sector must continue to improve, one of which is through the creation of innovation. Innovation in the public sector is carried out through the creation of ideas that cannot be separated from the knowledge sharing process. Knowledge sharing is important for organizations considering the nature of knowledge which is complementary and no single individual masters all fields of knowledge. Unfortunately, not many public agencies have implemented knowledge management properly through the use of information technology by considering organizational culture and the type of organizational structure. The purpose of this study was to examine how the influence of internalization of organizational culture and functional organizational structure on knowledge sharing capability at PT. PLN (Persero) Palembang Area by including information technology as an intervening variable. The method used in this study is a quantitative method using a questionnaire as primary data. The sample used in this study is a census sample so that the entire population is used as research respondents. The results showed that the use of information technology mediates the effect of internalization of organizational culture on knowledge sharing capabilities but does not mediate the effect of functional organizational structures on knowledge sharing capabilities. Based on these findings, the suggestions given by the researcher are: maximizing the use of information technology while maintaining a conducive organizational culture and climate for increasing knowledge sharing capabilities.

https://doi.org/10.24036/jmiap.v3i3.287 


\section{PENDAHULUAN}

Sejak akhir abad ke 20, terjadi perubahan yang sangat pesat yang membawa manusia pada era informasi dimana faktor yang sangat menonjol yaitu pengetahuan. Drucker (1993) melihat faktor pengetahuan sebagai satusatunya risorsis yang paling fundamental dalam kehidupan masyarakat era informasi atau yang sering disebut knowledge society. Kecenderungan ekonomi dunia yang kian ditopang oleh perkembangan ilmu pengetahuan dan teknologi sangat berpengaruh pada berbagai sektor kehidupan, tak terkecuali sektor publik. Nurmandi (2006) juga menyebutkan bahwa pesatnya perubahan ekonomi global dan nasional secara tidak langsung menghendaki adanya reformasi sektor publik. inovasi pada sektor publik tidak dapat dilepaskan dari faktor informasi dan pengetahuan sebagai intellectual capital dalam organisasi.

Dalam upaya melihat pengetahuan sebagai risorsis kapital yang krusial pada sebuah organisasi, PT. PLN (Persero) dirujuk oleh peneliti untuk menelaah aktivitas knowledge sharing. Dilandasi visi perusahaan, yaitu "Diakui sebagai perusahaan kelas dunia yang bertumbuh kembang, unggul dan terpercaya dengan bertumpu pada potensi insani", beberapa tahun terakhir PT. PLN (Persero) terus berupaya memperbaiki kinerja dengan menerapkan berbagai inovasi. Meyakini bahwa ketersediaan sumberdaya yang kompeten merupakan salah satu elemen strategis dalam menjawab tantangan usaha, PT. PLN (Persero) telah menyusun pengembangkan budaya berbagai pengetahuan (Knowledge Sharing) yang dijalankan sejak tahun 2005 dan terus dikembangkan hingga sekarang. Lebih luas lagi, PT. PLN (Persero) juga menerapkan Knowledge Management dalam proses bisnis penyusunan K-Taxonomy melalui pembangunan portal Knowledge Management System serta pada tahun 2011 PT. PLN (Persero) mengembangkan teknologi kolaboratif knowldege sharing dan KM audit.

Aktivitas pegawai PT. PLN (Persero) Area Palembang tidak dapat dilepaskan dari domain teknologi informasi. Hal ini ditunjukkan dari persentase penggunaan internet, email dan intranet organisasi yang sangat tinggi. Berdasarkan data yang dihimpun oleh peneliti dari kuesioner, sebanyak 84\% dari keseluruhan pegawai di PT. PLN (Persero) Area Palembang menggunakan internet, email dan intranet dengan intensitas yang tinggi, sisanya yaitu sebesar 16\% menggunakan dengan intensitas yang lebih rendah. Sebaliknya, Tri Kurniasih, kepala bagian SDM yang menjelaskan bahwa sekalipun portal KMS dapat diakses semua SDM, akan tetapi hanya sedikit yang aware, mau dan mampu memanfaatkan portal untuk menunjang aktivitas sharing knowledge di PT. PLN (Persero). Kedua hal tersebut mengindikasikan bahwa persentase yang tinggi atas penggunaan teknologi informasi ini tidak dibarengi dengan pemanfaatan yang maksimal atas portal Knowledge Management System (KMS) yang dapat diakses secara bebas oleh seluruh pihak PT. PLN (Persero).

Berbeda dengan asumsi- asumsi diatas, sebuah penelitian memperoleh temuan bahwa faktor organisasional tidak berpengaruh secara signifikan terhadap knowledge sharing. Dwimadyasari dan Susanty (2015) meneliti tentang pengaruh faktor organisasional, individual dan teknologikal terhadap knowledge sharing di PT. PLN (Persero). Temuan dari penelitian ini yaitu faktor individual dan faktor teknologikal mempunyai pengaruh yang signifikan terhadap knowledge sharing, sedangkan faktor organisasional tidak mempunyai pengaruh langsung dan signifikan terhadap knowledge sharing di PT. PLN.

Berbagai literatur dan kajian terkait knowledge sharing lebih banyak ditelaah dari aspek behavioral (Raharso dan Tjahjawati, 2016; Okyere-kwakye dan Nor, 2011; Bock dan Kim, 2002; Hsu dan Lin, 2008; Osterloch, M., \& Frey, B., 2000). Perhatian para peneliti terhadap knowledge sharing semakin meningkat, akan tetapi hanya sedikit literatur yang memfokuskan kajiannya pada kapabilitas knowledge sharing pegawai serta bagaimana pola hubungan konteks organisasional (budaya organisasi dan struktur organisasi) dan faktor teknologikal mempengaruhi kapabilitas knowledge sharing dalam organisasi.

\section{Konsep Pengetahuan}

Dalam literatur-literatur yang berkaitan dengan Knowledge Management, ada banyak definisi pengetahuan dari para pakar. Menurut pandangan Nonaka \& Takeuchi (1995), definisi klasik pengetahuan yaitu suatu keyakinan dan kepercayaan yang dibenarkan (A true, justified conviction or belief). Dalam konteks ini, pengetahuan lebih mengacu pada fakta- fakta, aturan pendapat dan temuan. Dengan penekanan yang sedikit berbeda, 
Buckley \& Carter (2003) menyebutkan "Knowledge is a quality possessed by people, literally a state of human mind". Dalam konteks ini, pengetahuan dimaknai sebagai suatu yang melekat dalam diri seseorang dan lebih merujuk pada konsep pengetahuan sebagai suatu risorsis yang abstrak. Sedangkan menurut Bergeron dalam Budihardjo (2016) pengetahuan adalah informasi yang diorganisasi, disintesiskan, atau diringkas untuk mendorong pemahaman terhadap suatu sasaran serta pengertian.

Klasifikasi pengetahuan yang paling sering digunakan oleh para pakar yaitu explicit knowledge dan tacit knowledge (Luen \& AlHawamdeh, 2001; Nonaka et al, 2006; Nurmandi, 2006; Dewah \& Mutula 2016; Budihardjo,2016). Tacit knowledge, yaitu pengetahuan yang digunakan oleh anggota organisasi untuk melaksanakan tugasnya, yang ditunjukkan dengan action based skill dan cenderung tidak dapat diverbalkan. Sedangkan Explicit knowledge, yaitu pengetahuan yang dapat diekspresikan dalam bentuk sistem simbol dan dapat dikomunikasikan serta disebarluaskan, baik yang berbasis pada objek maupun regulasi. Karena tacit knowledge bersifat abstrak maka perlu ada kodifikasi pengetahuan agar menjadi konkret/ nyata sehingga lebih mudah untuk disebarkan dan diseminasi secara lebih luas melalui berbagai sarana (Budihardjo, 2016).

\section{Kapabilitas Knowledge Sharing}

Kekayaan pengetahuan (intellectual asset) dalam organisasi harus disebarluaskan dan dibagikan. Hal ini karena tidak ada individu dalam organisasi yang menguasai semua bidang pengetahuan sedangkan pengetahuan itu sendiri bersifat komplementari (Buckley \& Charter, 2003) Lebih mendasar lagi, melalui aktivitas knowledge sharing, individu dalam organisasi dapat meningkatkan kapasitasnya untuk memahami situasi dan permasalahan serta mengaplikasikan pengetahuan yang diperoleh untuk menyikapi situasi atau permasalahan tertentu (Nonaka et al, 2006).

Terdapat banyak definisi dari para pakar tentang knowledge sharing. Menurut Hoof dan Ridder (2014) knowledge sharing merupakan suatu proses dimana individu secara mutual mempertukarkan pengetahuan (tacit maupun explisit) sehingga secara terpadu dapat menciptakan pengetahuan baru. Jadi knowledge sharing dipandang sebagai suatu proses saling berbagi pengetahuan baik antar individu maupun kepada organisasi untuk menciptakan tujuan bersama bagi organisasi yg ingin menggunakan aset pengetahuan untuk mencapai keunggulan kompetitif. Lin (2007:315) menyebutkan bahwa berbagi pengetahuan adalah suatu interaksi sosial untuk mempertukarkan pengetahuan dan ketrampilan antar individu dalam organisasi. Fokus yang ditekankan dari kedua pandangan adalah interaksi antar individu yang terkait dalam proses knowledge sharing.

Mempertimbangkan pentingnya proses knowledge sharing, baik organisasi publik maupun privat dipandang sangat perlu untuk melakukan penilaian terhadap kapabilitas knowledge sharing antar individu dalam organisasi (Kim dan Lee, 2006). Kapabilitas knowledge sharing akan menentukan efisiensi penciptaan pengetahuan (knowledge creation) dan manajemen pengetahuan dalam organisasi (Noor dan Salim, 2011). Sebagai pioneer dalam literatur terkait knowledge sharing capability (KSC), Kim dan Lee (2006) memaknai kapabilitas knowledge sharing sebagai suatu kemampuan dari individu untuk membagikan pengalaman- pengalam terkait pekerjaannya, keahlian, know-how dan informasi kontekstual dengan individu lain melalui interaksi formal maupun informal dalam satu tim atau lintas tim/ departemen. Tidak hanya membagi pengetahuannya, KSC juga terkait kemampuan individu untuk menggali atau memperoleh pengetahuan dari individu lain dalam satu divisi maupun pengetahuan yang dimiliki oleh divisi lain. Pandangan ini tidak terlepas dari terminologi Hoof dan Ridder (2004) bahwa proses knowledge sharing meliputi knowledge donating dan knowledge collecting.

\section{Faktor-faktor yang mempengaruhi kapabilitas knowledge sharing}

Para pakar knowledge management telah mengidentifikasi berbagai faktor yang mempengaruhi kapabilitas berbagi pengetahuan. Berbagai faktor yang diidentifikasi yaitu mulai dari faktor- faktor yang bersifat konkret (hard issues) seperti teknologi informasi dan alat, faktor- faktor yang bersifat abstrak (soft issues) seperti faktor organisasional dan individual serta penelitian yang berusaha menggabungkan keduanya. penelitian ini berusaha mengelaborasikan beberapa faktor yang mempengaruhi 
kapabilitas knowledge sharing dengan menggunakan kerangka model penelitian Kim dan Lee (2006), Hooff \& Ridder (2004) dan Noor \& Salim (2011). Selanjutnya faktorfaktor yang mempengaruhi kapabilitas knowledge sharing dikategorisasikan kedalam 3 kelompok dengan beberapa dimensi dan indikator yang melekat.

1) Faktor Budaya Organisasi

Budaya organisasi yang dikaji dalam penelitian ini difokuskan pada variabel internalisasi budaya organisasi. Dalam internalisasi budaya organsiasi, terdapat tiga komponen yang dinilai paling konsisten mempengaruhi kapabilitas knowledge sharing, yaitu kejelasan visi dan sasaran organisasi (Malhotra \& Segars, 2001; Stein \& Jock, 1992; Leonard;1995), Kepercayaan antar pegawai ( Stein\& Jock, 1992; O'dell and Grayson, 1998; Von Krogh, 1998; Bakhari and Zawiyah, 2008) dan jaringan sosial (O’Dell and Grayson, 1998; Leonard and Sensiper, 1998).

Organisasi didirikan berdasarkan tujuan tertentu sehingga kejelasan visi dan sasaran menjadi aspek krusial bagi setiap organisasi. Menurut Stein \& Jock (1992) seluruh visi organisasi akan menghasilkan arah organisasi yang jelas untuk mencapai tujuan masa mendatang yang diinginkan. Terkait aspek kepercayaan dan keterbukaan, Cohen dan Prusak (2001) menambahkan bahwa tingkat kepercayaan pegawai yang tinggi akan menggiring pada aktivitas knowledge sharing yang lebih baik dan menekan biaya- biaya. Aspek penting lain dalam budaya organisasi yaitu jaringan sosial.

2) Faktor Struktur Organisasi

Berdasarkan pemikiran Kim dan Lee (2006) dan penelitian para pakar lainnya, terdapat tiga aspek yang paling mempengaruhi kapabilitas knowledge sharing dalam struktur organisasi. Ketiga aspek dalam domain struktur organisasi yang mempengaruhi knowledge sharing yaitu: desentralisasi, fleksibilitas dan sistem reward berbasis kinerja. Ketiga aspek ini juga merupakan cerminan dari struktur organisasi fungsional. Terkait hal ini, Steiger et al (2014) menjelaskan bahwa struktur fungsional menekankan kemampuan dan ketrampilan pegawai. Otonomi yang luas pada tipe struktur fungsional menjadi suatu kekuatan sekaligus kelemahan. Steiger et al (2014) mengemukakan: Autonomy can enable individuals to think freely and take risk, but it can also lead to the misuse of discretion. Jadi dapat ditarik sebuah poin penting bahwa dalam struktur fungsional otonomi memungkinkan individu untuk berfikir secara bebas dan mengambil resiko, akan tetapi hal ini juga memungkinkan adanya penyalahgunaan diskresi.

Dua aspek penting yang harus diperhatikan dalam domain teknologi informasi yaitu: pertama, penggunaan aplikasi teknologi informasi (IT application usage). Menurut Noor dan Salim (2011), penggunaan aktif aplikasi berbasis teknologi informasi akan mempengaruhi kemampuan pegawai dalam berbagi pengetahuan karena pegawai cenderung lebih nyaman untuk berkomunikasi secara online daripada interkasi tatap muka secara langsung. Aplikasi yang banyak digunakan untuk mendukung knowledge sharing yaitu: Electronic Data Management System (EDMS), meeting system, internet based knowledge system, electronic publishing system dan lain sebagainya (Wiig, 1999).

Kedua, level fokus pengguna akhir (enduser focus) terhadap sistem teknologi informasi. King dalam Kim dan Lee (2016) menjelaskan bahwa desain sistem manajemen pengetahuan yang secara tepat sesuai dengan kebutuhan pengguna adalah faktor yang sangat penting dan memberikan keuntungan pada sistem itu sendiri. Para pengembang software dan sistem IT harus menciptakan produk yang ramah pengguna (user-friendly) agar dapat meningkatkan penerimaan dan penggunaan sistem tersebut (King, 1999) 


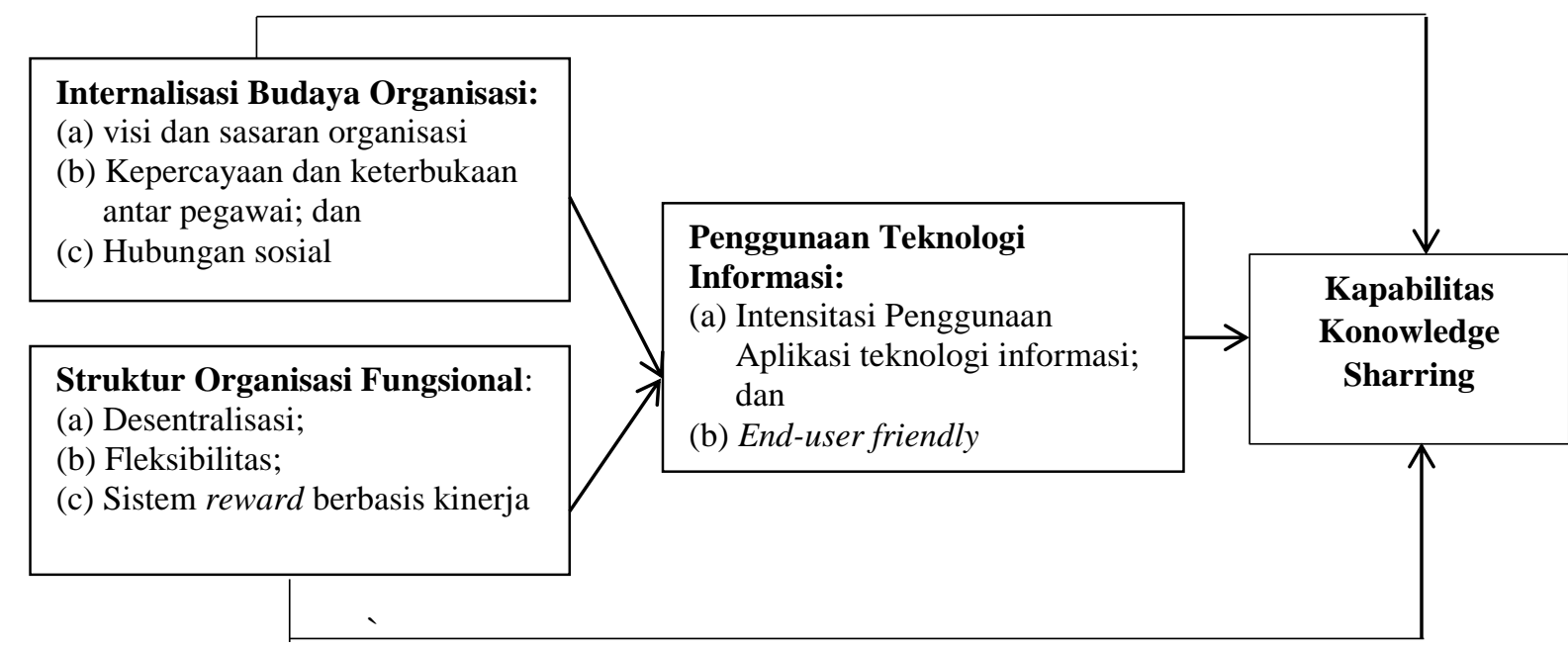

Gambar 1. Kerangka Model Penelitian

Model penelitian yang digambarkan pada Gambar 1 diatas dimodifikasi dari model penelitian Kim dan lee (2016); Noor dan Salim (2011) dan variabel Kapabilitas Knowledge Sharing diadopsi dari Hooff dan Ridder (2004). Pada penelitian terdahulu, ketiga dimensi (budaya, struktur dan teknologi informasi) berperan sama sebagai variabel Internalisasi Budaya Organisasi: (a) visi dan sasaran organisasi (b) Kepercayaan dan keterbukaan antar pegawai; dan (c) Hubungan sosial Struktur Organisasi Fungsional: (a) Desentralisasi; (b) Fleksibilitas; dan (c) Sistem reward berbasis kinerja Penggunaan Teknologi Informasi: (a) Intensitas Penggunaan aplikasi teknologi informasi; dan (b) End-user friendly Kapabilitas knowledge sharing Gambar 1. Kerangka Model Penelitian Sumber: Kim dan lee (2016); Noor dan Salim (2011); dan Hooff dan Ridder (2014). Hidayah- Knowledge Sharing Pegawai di PT PLN (Persero) Area Palembang independen, akan tetapi penelitian ini melakukan modifikasi dengan menggunakan variabel penggunaan tekonologi informasi sebagai variabel intervening. Hal ini didasari oleh beberapa penelitian terdahulu, salah satunya penelitian Dwimadyasari \& Susanty (2015) yang menemukan temuan menarik bahwa dimensi organisasional tidak berpengaruh secara langsung terhadap kapabilitas knowledge sharing serta banyak penelitian lain yang mempertegas temuan bahwa penggunaan teknologi informasi signifikan mempengaruhi aktivitas knowledge sharing Wiig (1999); King (1999); Kim dan Lee (2016); Noor dan Salim (2011); dan banyak peneliti lainnya.

\section{METODE PENELITIAN}

Dalam penelitian ini penulis menggunakan pendekatan kuantitatif, yaitu dengan menggunakan kuesioner sebagai instrumen penelitian yang utama dan mengolah angkaangka yang diperoleh dengan menggunakan statistik. Penelitian ini merupakan studi persepsian (perceptual study), dimana semua data yang diperoleh merupakan persepsi responden tentang item- item pernyataan yang ada dalam kuesioner. Sampel yang digunakan dalam penelitian ini adalah sampel populasi, semua pegawai PT. PLN (Persero) Area Palembang yang berjumlah 80 . Ketika individu-individu dipilih dari suatu populasi, sebaiknya identifikasi karakteristik yang digunakan untuk menstratifikasi populasi, seperti: gender, pendidikan, posisi/ jabatan (Creswell, 2010). Metode pengambilan data dengan menggunakan semua anggota populasi seringkali disebut sampling jenuh atau sensus. Menurut Maskum (2012), sensus adalah suatu cara pengumpulan data yang dilaksanakan dengan mencatat seluruh populasi yang ada. Cara ini umumnya digunakan untuk pengembangan data dasar seperti sensus penduduk, sensus sosialekonomi dan berbagai pendataan yang dilakukan oleh Badan Pusat Statistik. Teknik sensus juga seringkali digunakan ketika jumlah populasi tidak terlalu banyak sehingga Memungkinkan bagi peneliti untuk menggunakan semua populasi agar data yang diperoleh lebih representatif.

Menurut Sarwono (2016), data dikelompokkan menjadi dua jenis, yaitu data primer dan data sekunder. Data primer adalah data yang berasal dari sumber asli atau pertama sedangkan data sekunder adalah data yang 
sudah tersedia sehingga peneliti tinggal menghimpun dan menyaring sesuai kebutuhan penelitian misalnya data tentang identitas pegawai, struktur organisasi, dokumen perencanaan, dan lain sebagainya. Proses yang dilakukan pertama kali yaitu menyampaikan surat ijin secara langsung kepada bagian penelitian/ magang yang telah disetujui oleh dosen pembimbing dan pihak universitas. Setelah surat ijin disetujui, proses berikutnya adalah penyebaran kuesioner serta menghimpun kembali kuesioner yang telah diisi oleh responden. Selanjutnya, untuk menghimpun data- data sekunder dalam penelitian ini, penulis mengutip beberapa metode yang dijelaskan oleh Sarwono (2016) yaitu pencarian secara manual dan pencarian secara online. Peneliti juga akan menghimpun materi-materi audio-visual, misalnya berupa aplikasi komputer yang menunjang proses knowledge sharing, dokumentasi- dokumentasi terkait pelaksanaan knowledge sharing dan data online lainnya.

Variabel harus didefiniskan secara operasional agar dapat diperoleh pemaknaan yang didasarkan pada karakteristik yang dapat diobservasi oleh peneliti (Sarwono, 2016). Tanpa operasionalisasi variabel, peneliti akan mengalami kesulitan dalam menentukan pengukuran hubungan antar variabel yang masih bersifat konseptual. Berikut definisi operasional dari variabel internalisasi budaya organisasi, struktur organisasi fungsional, penggunaan teknologi informasi dan kapabilitas knowledge sharing beserta pengukuran masing-masing variabel penelitian

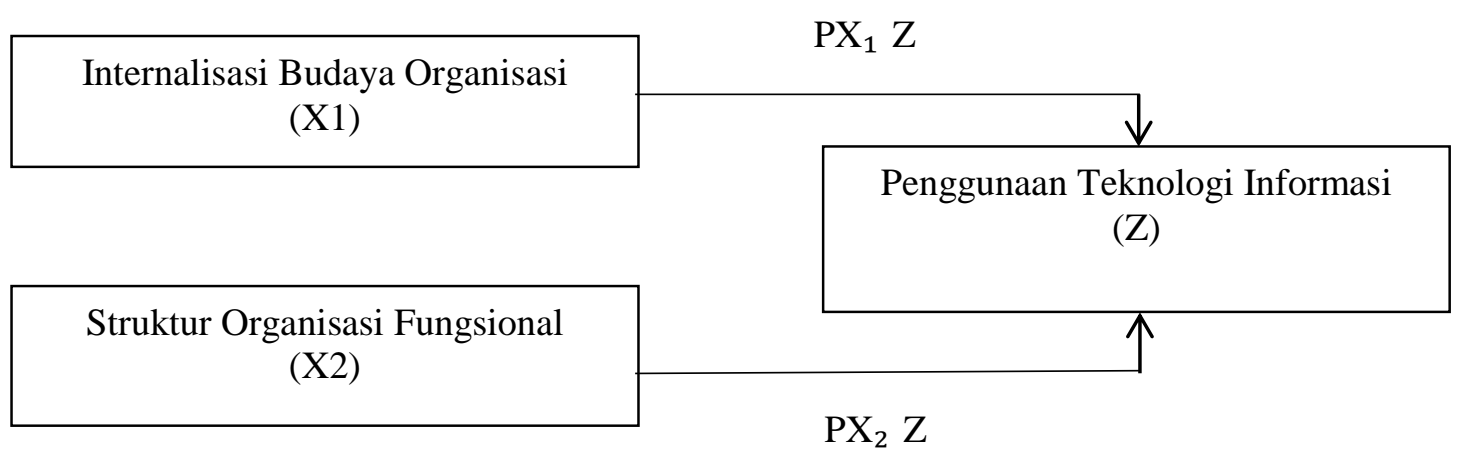

Gambar 2. Definisi Operasional dan Skala Pengukuran

\section{Internalisasi Budaya Organisasi}

Internalisasi budaya organisasi dalam penelitian ini didefiniskan sebagai suatu proses belajar untuk menjiwai nilai-nilai kebudayaan yang tertuang dalam konstruksi utuh yang digerakkan oleh visi dan tujuan organisasi sehingga membentuk pola bertindak, pola perilaku, kepercayaan yang diyakini bersama dan pandangan sekelompok orang untuk merespon lingkungan internal dan eksternal organisasi melalui interaksi/ hubungan sosial. Variabel internalisasi budaya organisasi diukur dengan menggunakan tiga indikator: visi dan tujuan oganisasi, kepercayaan dan hubungan sosial. Indikator-indikator ini dioperasionalisasikan melalui 12 item pernyataan yang diadaptasi dari Gold, et al (2001); Cook dan Wall (1980) dalam Kim dan Lee (2016).

\section{Struktur Organisasi Fungsional}

Struktur organisasi fungsional dalam penelitian ini didefinisikan sebagai suatu tipe organisasi yang ditandai dengan adanya pembagian tugas berdasarkan fungsi, ketrampilan dan keahlian untuk menjelasakan pengaturan kewenangan dan fungsi masingmasing elemen, bagaimana mekanisme tugastugas dilaporkan dan dialokasikan untuk selanjutnya sebagai pedomaan pemberian reward berbasis pada kinerja. Variabel struktur organisasi fungsional diukur dengan menggunakan tiga indikator dan 14 item pernyataan yang diadaptasi dari Hage dan Aiken (1967) dalam Kim dan Lee (2016). Penggunaan Teknologi Informasi Variabel ini digunakan untuk mengukur keaktifan dan intensitas penggunaan aplikasi teknologi informasi yang telah difasilitasi oleh organisasi untuk menunjang kelancaran komunikasi dan efektifitas penyebaran informasi dan pengetahuan. Aplikasi teknologi informasi sebagai penunjang saluran informasi dan komunikasi antar pegawai dapat berupa database organisasi, Electronic Data Management System (EDMS), media buletin 
online, grup diskusi online, e-mail dan lain sebagainya. Penggunaan teknologi informasi diukur dengan menggunakan dua indikator dan 6 item pernyataan yang direplika dari Kim dan lee (2016).

\section{Kapabilitas Knowledge Sharing}

Kapabilitas knowledge sharing adalah Suatu kemampuan dan kemauan individu untuk membagikan pengetahuannya, baik berupa pengalaman terkait pekerjaannya, keahlian, know-how dan informasi kontekstual dengan individu lain melalui interaksi formal maupun informal dalam satu tim atau lintas tim/ departemen. Tidak hanya membagi pengetahuannya, kapabilitas knowledge sharing juga terkait kemampuan individu untuk menggali atau memperoleh pengetahuan dari individu lain dalam satu divisi maupun pengetahuan yang dimiliki oleh divisi lain.

Variabel kapabilitas knowledge sharing diukur dengan menggunakan dua indikator dan 10 item pernyataan yang diadaptasi dari Hooff dan Ridder (2014). Respon terhadap penyataan- pernyataan dalam kuesioner menggunakan skala Likert dengan 5 skala, yaitu $1=$ sangat tidak setuju; $2=$ tidak setuju; $3=$ netral; $4=$ setuju, dan $5=$ sangat setuju.

Baron \& Kenny dalam Supriyono (2004) menyebutkan bahwa suatu variabel berfungsi sebagai pemediasi atau variabel intervening jika: (1) variabel bebas (X) secara signifikan berhubungan dan mempengaruhi variabel intervening; (2) variabel intervening secara signifikan berhubungan dan mempengaruhi variabel terikat $(\mathrm{Y})$, dan (3) hubungan antara variabel bebas dengan variabel terikat menurun setelah dikontrol dengan variabel intervening.

\section{HASIL DAN PEMBAHASAN \\ Hasil}

Pengujian hipotesis pada penelitian ini menggunakan uji regresi yang dilanjutkan dengan analisis jalur (Path Analysis) dengan bantuan program SPSS. Analisis jalur merupakan perluasan dari analisis regresi berganda yang bertujuan untuk mengukur besar dan kecilnya pengaruh serta signifikansi hubungan antar beberapa variabel dengan melibatkan variabel mediasi atau yang sering disebut dengan intervening variable. Teknik path analysis digunakan untuk mengestimasi ada tidaknya pengaruh mediasi, mengukur pengaruh langsung (direct effect), pengaruh tidak langsung (indirect effect) serta pengaruh total diantara beberapa variabel. Melalui olah data dengan analisis jalur, peneliti dapat mengetahui seberapa besar koefisien masingmasing variabel terhadap variabel lain atau disebut dengan (path coefficient).

Langkah pengujian analisis jalur dimulai dengan memecah uji regresi menjadi 2 substruktur yaitu: (1) Pengaruh internalisasi budaya organisasi (X1) dan struktur organisasi fungsional (X2) terhadap penggunaan teknologi informasi (Z), dan (2) Pengaruh internalisasi budaya organisasi (X1), struktur organisasi fungsional (X2) dan penggunaan teknologi informasi (Z) terhadap kapabilitas knowledge sharing $(\mathrm{Y})$.

Tabel 1. Hasil Uji Regresi Sub. Struktur 1 COEFFISIENTS

\begin{tabular}{|c|c|c|c|c|c|c|}
\hline & \multirow[t]{2}{*}{ MODEL } & \multicolumn{2}{|c|}{$\begin{array}{l}\text { Unstandarlized } \\
\text { Coeffisients }\end{array}$} & \multirow{2}{*}{$\begin{array}{c}\text { Standarized } \\
\text { Coeffisients } \\
\text { Beta } \\
\end{array}$} & \multirow[t]{2}{*}{$\mathbf{T}$} & \multirow[t]{2}{*}{ Sig. } \\
\hline & & B & Std. Error & & & \\
\hline \multirow[t]{3}{*}{1} & (Constants) & 2,069 & 3,373 & - & ,613 &, 542 \\
\hline & $\begin{array}{c}\text { Int. Budaya Org. } \\
\text { (X1) }\end{array}$ & ,318 & ,061 & ,551 & 5,232 &, 000 \\
\hline & $\begin{array}{c}\text { Struktur Org. } \\
\text { Fungsional (X2) }\end{array}$ & ,123 & ,051 & ,255 & 2,420 & ,019 \\
\hline
\end{tabular}

\section{A. DEPENDENT VARIABLE IT_USE}

(Sumber: Diolah Penulis dari data Primer)

Berdasarkan hasil uji regresi pada tabel 1, maka diperoleh persamaan regresi untuk substruktur 1, yaitu $Z=2,069+0,318 \mathrm{PX} 1 \mathrm{Z}+$ $0,123 \mathrm{PX} 2 \mathrm{Z}+\mathrm{e}$. Nilai r square menunjukkan angka 0,421 atau $42,1 \%$. Hal ini berarti bahwa penggunaan teknologi informasi (Z) dipengaruhi oleh internalisasi budaya organisasi (X1) dan struktur organisasi 
fungsional (X2) sebesar 42,1\%. Sedangkan sisanya, sebesar 57,9 \% dipengaruhi oleh variabel lain diluar model ini. Selanjutnya, persamaan struktural untuk sub- struktur 2 adalah $\mathrm{Y}=\alpha+\mathrm{PX} 1 \mathrm{Y}+\mathrm{PX} 2 \mathrm{Y}+\mathrm{PZY}+\mathrm{e}$, dengan kerangka model regresi sebagaimana terdapat dalam Gambar 3.

Tabel 2. Hasil Uji Regresi Sub-Struktur 2

COEFFICIENTSA

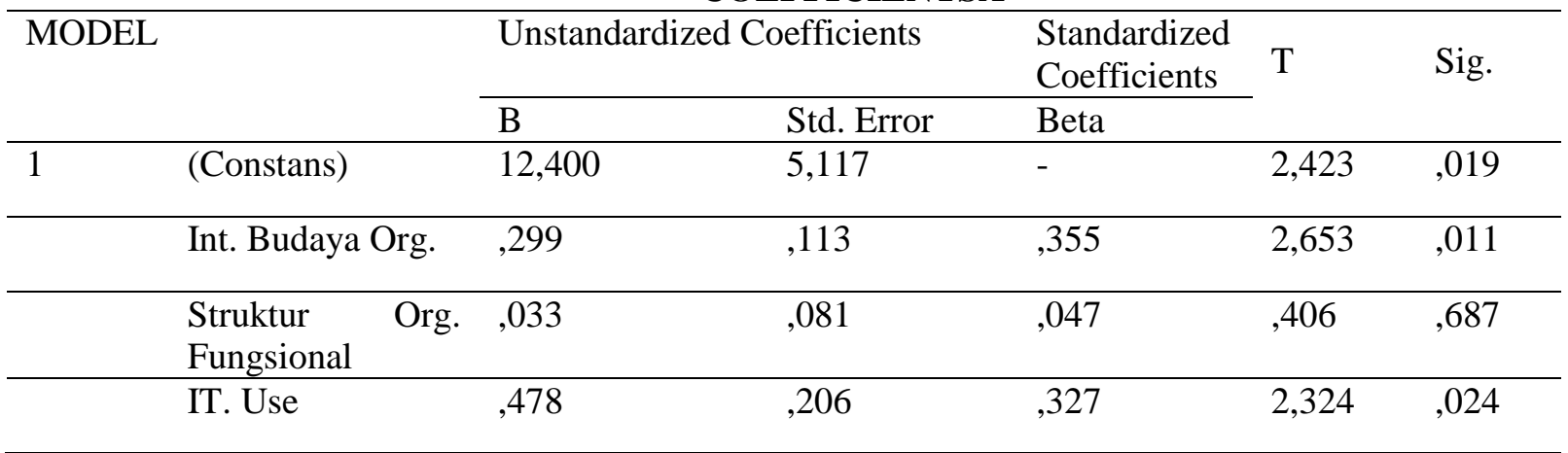

\section{A. DEPENDENT VARIABLE: KNOWLEDGE SHARING}

(Sumber: diolah penulis dari data primer)

Berdasarkan hasil uji regresi sub-struktur 2 pada tabel 2, maka diperoleh persamaan regresi untuk sub-struktur 2, yaitu $\mathrm{Y}=12,400$ $50+0,299$ PX1Y + 0,033 PX2Y + 0,478 ZY+ e. Nilai $\mathrm{R}$ square menunjukkan angka 0,391 atau sama dengan 39,1\%. Hal ini berarti bahwa kapabilitas knowledge sharing (Y) dipengaruhi oleh internalisasi budaya organisasi (X1), struktur organisasi fungsional (X2) dan penggunaan teknologi informasi (Z) sebesar 39,1\%. Sedangkan sisanya, sebesar $60,9 \%$ dipengaruhi oleh variabel lain diluar model ini. Selanjutnya, hasil kedua uji regresi berganda tersebut digunakan untuk membuktikan pasangan hipotesis pertama sampai kelima dengan menggunakan uji sobel.

Hipotesis pertama yang diuji yaitu "Internalisasi Budaya organisasi mempunyai pengaruh signifikan terhadap kapabilitas knowledge sharing". Hipotesis ini diuji melalui uji regresi sub-struktur 2 pada jalur PX1Y. Berdasarkan hasil perhitungan analisis regresi yang disajikan pada tabel 3, dapat diinterpretasikan bahwa: Hasil pengujian hipotesis menunjukkan bahwa nilai t hitung variabel budaya organisasi sebesar 2,653 lebih besar daripada nilai $t$ tabel yaitu 2,004 dan signifikansi sebesar $0,011(0,011<0,05)$. Dari hasil ini dapat disimpulkan bahwa variabel internalisasi budaya organisasi berpengaruh signifikan terhadap kapabilitas knowledge sharing sehingga $\mathrm{H} 1$ diterima dan $\mathrm{H} 0$ ditolak.

Hipotesis kedua yang diuji yaitu "Struktur organisasi fungsional mempunyai pengaruh signifikan terhadap kapabilitas knowledge sharing”. Hipotesis ini diuji melalui uji regresi sub-struktur 2 pada jalur PX2Y. Berdasarkan tabel hasil perhitungan analisis regresi yang disajikan pada tabel 3, dapat diinterpretasikan bahwa: Hasil pengujian hipotesis menunjukkan bahwa nilai $t$ hitung variabel struktur organisasi fungsional sebesar 0,406 lebih kecil daripada nilai $\mathrm{t}$ tabel yaitu 2,004 dan signifikansi sebesar 0,687 $(0,687>0,05)$. Dari hasil ini dapat disimpulkan bahwa $\mathrm{H}_{1}$ ditolak dan $\mathrm{H}_{0}$ diterima, artinya variabel struktur organisasi tidak berpengaruh terhadap kapabilitas knowledge sharing.

Hipotesis ketiga yang diuji yaitu "Internalisasi budaya organisasi berpengaruh signifikan terhadap penggunaan teknologi informasi". Hipotesis ini diuji melalui uji regresi sub-struktur 1 pada jalur PX1Z. Berdasarkan tabel hasil perhitungan analisis regresi yang disajikan pada tabel 5.3, dapat diinterpretasikan bahwa: Hasil pengujian hipotesis menunjukkan bahwa nilai t hitung variabel internalisasi budaya organisasi sebesar 5,232 lebih besar daripada nilai t tabel yaitu 2,004 dan signifikansi sebesar $0,000(0,000<$ 0,05). Dari hasil ini dapat disimpulkan bahwa variabel budaya organisasi berpengaruh signifikan terhadap penggunaan teknologi informasi sehingga $\mathrm{H}_{1}$ diterima dan $\mathrm{H}_{0}$ ditolak.

Hipotesis keempat yang diuji yaitu "Struktur organisasi fungsional berpengaruh signifikan terhadap penggunaan teknologi informasi”. 
Hipotesis ini diuji melalui uji regresi substruktur 1 pada jalur PX2Z. Berdasarkan tabel hasil perhitungan analisis regresi yang disajikan pada tabel 2, dapat diinterpretasikan bahwa: Hasil pengujian hipotesis menunjukkan bahwa nilai $\mathrm{t}$ hitung variabel struktur organisasi fungsional sebesar 2,420 lebih besar daripada nilai $t$ tabel yaitu 2,004 dan signifikansi sebesar $0,019(0,019<0,05)$. Dari hasil ini dapat disimpulkan bahwa variabel struktur organisasi funhgsional berpengaruh signifikan terhadap penggunaan teknologi informasi sehingga $\mathrm{H}_{1}$ diterima dan $\mathrm{H}_{0}$ ditolak.

Hipotesis kelima yang diuji yaitu "Penggunaan teknologi informasi memiliki pengaruh signifikan terhadap kapabilitas knowledge sharing". Hipotesis ini diuji melalui uji regresi sub-struktur 2 pada jalur PZY. Berdasarkan tabel hasil uji regresi yang disajikan pada tabel 3, dapat diinterpretasikan bahwa: Hasil pengujian hipotesis menunjukkan bahwa nilai $t$ hitung variabel penggunaan teknologi informasi sebesar 2,324 lebih besar daripada nilai $\mathrm{t}$ tabel yaitu 2,004 dan signifikansi sebesar 0,024 $(0,024<0,05)$. Dari hasil ini dapat disimpulkan bahwa variabel penggunaan teknologi infrmasi berpengaruh signifikan terhadap kapabilitas knowledge sharing sehingga $\mathrm{H}_{1}$ diterima dan $\mathrm{H}_{0}$ ditolak.

Hipotesis keenam yang diuji yaitu "Internalisasi budaya organisasi mempunyai pengaruh signifikan terhadap kapabilitas knowledge sharing melalui penggunaan teknologi informasi sebagai variabel intervening. Untuk menguji hipotesis ini maka penulis menggunakan beberapa rumus pada uji sobel. Pertama, mencari nilai standar eror pengaruh tidak langsung (indirect effect) dengan rumus sebagai berikut: $\mathrm{Sab}=$ $\sqrt{b^{2} s a^{2}+a^{2} s b^{2}+s a^{2} s b^{2}}$

Ket:

$a=$ koefisien regresi variabel independen terhadap variabel mediasi $\left(\mathrm{PX}_{1} \mathrm{Z}\right)$

$\mathrm{b}=$ keofisien regresi variabel mediasi terhadap variabel dependen (PZY)

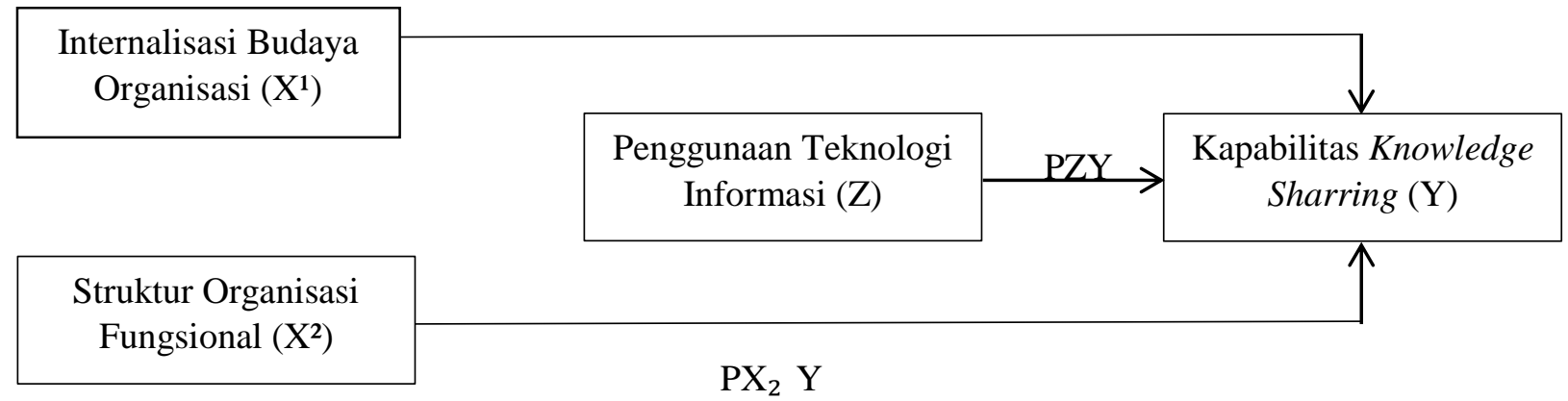

Gambar 3. Kerangka Sub-Struktur 2

(Sumber: Diolah Penulis, 2021)

$\mathrm{sa}=\mathrm{standar}$ error of estimation dari pengaruh variabel indepen terhadap variabel mediasi $\mathrm{sb}=\mathrm{standar}$ error of estimation dari pengaruh variabel mediasi terhadap variabel dependen Sehingga diperoleh nilai $\mathrm{Sab}=0,073$ Untuk menguji signifikansi pengaruh tidak langsung, maka perlu diketahui nlai $\mathrm{z}$ dari koefisien ab dengan rumus:

$\mathrm{Z}=\frac{a b}{s a b}$

$\mathrm{Z}=\frac{0,318 \times 0,478}{0,073}$

$\mathrm{z}=2,082$

Jika z hitung lebih besar dari z mutlak/ z kurva normal yaitu 1,96, maka terjadi pengaruh mediasi dari X1 terhadap Y melalui Z. Karena 2,082 > 1,96 maka terjadi pengaruh mediasi dari variabel internalisasi budaya organisasi terhadap kapabilitas knowledge sharing melalui penggunaan teknologi informasi sebagai variabel intervening sehingga $\mathrm{H}_{0}$ ditolak dan $\mathrm{H}_{1}$ diterima.

Hipotesis terakhir yang diuji yaitu "Struktur organisasi fungsional berpengaruh positif dan signifikan terhadap kapabilitas Knowledge sharring melalui penggunaan teknologi informasi sebagai variabel intervening". Untuk menguji hipotesis ini, langkah yang digunakan sama dengan uji hipotesis sebelumnya.

$\mathrm{Sab}=\sqrt{b^{2} s a^{2}+a^{2} s b^{2}+s a^{2} s b^{2}}$

$a=$ koefisien regresi variabel independen terhadap variabel mediasi (PX2Z)

$\mathrm{b}=$ keofisien regresi variabel mediasi terhadap variabel dependen (PZY)

$\mathrm{sa}=$ standar error of estimation dari pengaruh variabel indepen terhadap variabel mediasi 
$\mathrm{sb}=\mathrm{standar}$ error of estimation dari pengaruh variabel mediasi terhadap variabel dependen.

Sehingga diperoleh hasil perhitungan sebagai berikut: $\mathrm{Sab}=0,038$. Untuk menguji signifikansi pengaruh tidak langsung, maka perlu diketahui nlai $\mathrm{z}$ dari koefisien ab dengan rumus:

$\mathrm{Z}=\frac{a b}{s a b}$

$\mathrm{Z}=\frac{0,123 \times 0,478}{0,038}$

$\mathrm{z}=1,55$

Jika z hitung lebih besar dari z kurva normal $(1,96)$, maka terjadi pengaruh mediasiri X2 terhadap Y melalui Z. Karena 1,55<1,96 maka tidak terjadi pengaruh mediasi dari variabel struktur organisasi terhadap kapabilitas knowledge sharing melalui penggunaan teknologi informasi sebagai variabel intervening sehingga $\mathrm{H}_{0}$ diterima dan $\mathrm{H}_{1}$ ditolak.

\section{Pembahasan}

Pembahasan dilakukan berdasarkan hasil pengujian hipotesis dan pengujian tambahan yang telah dilakukan sebelumnya. Hasil yang diperoleh dari pengujian hipotesis adalah terdapat dalam Tabel 4.

Uji signifikansi internalisasi budaya organisasi terhadap kapabilitas knowledge sharing menunjukkan bahwa internalisasi budaya organisasi mempunyai pengaruh signifikan terhadap kapabilitas knowledge sharing sehingga $\mathrm{H}_{0}$ ditolak dan $\mathrm{H}_{1}$ diterima. Temuan ini konsisten dengan pandangan dan atau hasil penelitian DeLong (1997); Ikhsan \& Rowland (2004); Sharrat \& Usoro (2003); McDermottdan O'Dell (2001); Davenport et al (1996) dan Mannie et al (2013).

Budaya organisasi diukur dari kejelasan visi, tingkat kepercayaan dan hubungan sosial. Dari ketiga indikator ini, indikator dengan pengaruh terbesar terhadap kapabilitas knowledge sharing yaitu kejelasan visi. Indikator ini memberikan mempunyai koefisien pengaruh tertinggi dibandingkan dengan kedua indikator lainnya, yaitu sebesar 0,333 . Artinya, kejelasan visi organisasi serta pemahaman pegawai pada visi dan misi organisasi akan berpengaruh pada kapabilitas knowledge sharing pegawai. Visi PT. PLN "Diakui sebagai perusahaan kelas dunia yang bertumbuh kembang, unggul, dan terpercaya dengan bertumpu pada potensi insani" sejalan dengan esensi knowledge sharing yang menekankan pada potensi intelektual sumber daya manusia. Temuan ini sejalan dengan pandangan Davenport et al (1996) dan O'Dell dan Grayson (1998) bahwa kejelasan visi dan tujuan organisasi penting untuk meningkatkan keterlibatan dan konstribusi karyawan dalam menyebarkan informasi.

Uji pasangan hipotesis kedua menunjukkan bahwa struktur organisasi fungsional tidak mempunyai pengaruh signifikan terhadap kapabilitas knowledge sharing sehingga $\mathrm{H}_{0}$ diterima dan $\mathrm{H}_{1}$ ditolak. ini. Artinya, struktur organisasi yang diukur dengan derajat desentralisasi, fleksibilitas, dan penerapan reward berbasis kinerja tidak berpengaruh terhadap kapabilitas knowledge sharing tetapi jika dirinci berdasarkan masingmasing loading factornya, indikator penerapan reward berbasis kinerja mempunyai pengaruh terhadap kapabilitas knowledge sharing dengan nilai koefisien regresi yang mencapai 0,430.

Yang perlu diperhatikan dalam temuan ini bahwa instrumen penelitian untuk menguji variabel struktur organisasi hanya meneliti satu dimensi struktur organisasi. Tipe struktur yang diukur dalam instrumen penelitian ini dapat diklasifikasikan pada tipe divisional structure berdasarkan klasifikasi dari Steiger et al (2014), yaitu struktur organisasi yang terbagi dalam beberapa divisi dengan tetap mengedepankan kontrol, fungsionalisasi dan formalisasi. Hasil penelitian yang dilakukan oleh Steiger et al (2014) menyebutkan bahwa praktek knowledge management yang meliputi aktivitas knowledge transfer, knowledge sharing, information filtering dan knowledge culture dipengaruhi oleh tipe struktur organisasi. Steiger et al (2014) dalam penelitiannya mengklasifikan struktur organisasi dalam 5 tipe, yaitu adhocracy, strategic business unit (SBU), divisional, functional \& matrix. Temuan pada uji hipotesis kedua ini ternyata juga mengkonfirmasi sebuah antitesa yang diperoleh dari penelitian ClaverCortes et al (2007) yang menyebutkan bahwa organisasi dengan bentuk atau struktur yang fleksibel dengan level hierarki yang kecil serta mengembangkan penilaian berdasar kompetensi akan mendorong komunikasi dan teamwork antara pegawai dalam organisasi. Instrumen yang diadopsi dari Kim dan Lee (2006) menggunakan ukuran sentralisasi dan formalisasi yang merupakan kebalikan dari apa yang diukur dalam penelitian yang dilakukan Claver- Cortes et al (2007). 
Uji ketiga menunjukkan bahwa internalisasi budaya organisasi berpengaruh signifikan terhadap penggunaan teknologi informasi sehingga $\mathrm{H}_{0}$ ditolak dan $\mathrm{H}_{1}$ diterima ini. Dari ketiga indikator internalisasi budaya organisasi (kejelasan visi, tingkat kepercayaan dan hubungan sosial), hubungan sosial mempunyai koefisien regresi tertinggi yang mempengaruhi penggunaan teknologi informasi, yaitu sebesar 0,440 dengan sig 0,001. Berdasarkan perhitungan ini, artinya semakin aktif pegawai melakukan hubungan sosial, baik melalui pertemuan formal maupun informal dalam organisasi, maka tingkat penggunaan teknologi informasi dalam organisasi akan semakin tinggi. Hasil uji hipotesis ketiga ini konsisten dengan penelitian terdahulu yang dilakukan oleh Odedra (1992); Kim dan Lee (2006) dan Magni et al (2016). Magni et al (2016) menegaskan bahwa untuk merespon perkembangan teknologi informasi, individu dalam organisasi akan cenderung mengandalkan rekan kerjanya sehingga hubungan sosial antar pegawai dalam organisasi mempengaruhi intensitas dan kemampuan penggunaan teknologi infomasi.

Hasil uji signifikansi struktur organisasi fungsional terhadap penggunaan teknologi informasi menunjukkan temuan bahwa struktur organisasi fungsional berpengaruh signifikan terhadap penggunaan teknologi informasi sehingga $\mathrm{H}_{0}$ ditolak dan $\mathrm{H}_{1}$ diterima. Artinya, struktur organisasi fungsional yang baik akan menggiring organisasi pada aktivitas pemanfaatan teknologi informasi yang tinggi. Setelah dihitung pengaruh masing- masing indikator, dapat diketahui bahwa penerapan reward berbasis kinerja merupakan indikator dengan loading factor tertinggi jika dibandingkan dengan kedua indikator lainnya, dengan nilai koefisien regresi sebesar 0,487 dan sig 0,000. Artinya, semakin baik sistem reward berbasis kinerja diterapkan, maka penggunaan teknologi informasi juga akan semakin maksimal. Hal ini sejalan dengan pemikiran Buckley dan Carter (2013) bahwa adanya perkembangan sistem IT yang semakin kompleks dan 'sophisticated' untuk menyimpan dan menyebarkan informasi tidak akan pernah berhasil tanpa adanya kepedulian yang besar (great care), konsultasi serta penerapan sistem insentif pegawai yang tepat. Hasil uji hipotesis keempat ini juga konsisten dengan penelitian terdahulu yang dilakukan oleh Kim dan Lee (2016) dan Oberg \& Walgenbach (2008).

Uji hipotesis kelima yang menguji pengaruh variabel mediasi terhadap variabel terikat juga terbukti signifikan sehingga $\mathrm{H} 0$ ditolak dan H1 diterima Artinya, penggunaan teknologi informasi memiliki pengaruh signifikan terhadap kapabilitas knowledge sharing pegawai. Penggunaan teknologi informasi diukur dengan dua indikator, yaitu intensitas penggunaan sistem informasi online dan kemudahan aplikasi yang digunakan pegawai. Dari dua indikator ini, kemudahan aplikasi (end user freindly) mempunyai loading factor tertinggi dalam mempengaruhi kapabilitas knowledge sharing, dengan koefisien regresi sebesar 0,465 dan sig 0,001. Artinya, semakin mudah suatu aplikasi dan sistem informasi dirancang, maka akan meningkatkan aktivitas dan kapabilitas knowledge sharing pegawai dalam organisasi. Media sosial sebagai salah satu alat (tool) yang mudah diaplikasikan dalam aktivitas berbagi pengetahun juga akan sangat membantu meningkatkan kapabilitas knowledge sharing pegawai. Seperti ditegaskan oleh Razmerita et al (2016) bahwa pemanfaatan social media akan memfasilitasi pengelolaan dan eksternalisasi pengetahuan, baik pengetahuan individu maupun pengetahuan organisasi. Temuan ini juga konsisten dan berhasil mengkonfirmasi penelitian terdahulu yang dilakukan oleh Alavi \& Leidner (2001); Noor dan Salim (2011); Parsons et al,( 2008) dan Kim dan Lee (2016).

Uji pengaruh mediasi variabel teknologi informasi yang memediasi pengaruh internalisasi budaya organisasi terhadap kapabilitas knowledge sharing terbukti signifikan sehingga $\mathrm{H}_{0}$ ditolak dan $\mathrm{H}_{1}$ diterima. Berdasarkan path analysis dan uji sobel, terbukti bahwa internalisasi budaya organisasi mempunyai pengaruh yang positif dan signifikan terhadap kapabilitas knowledge sharing melalui penggunaan teknologi informasi sebagai variabel intervening. Artinya, penggunaan teknologi informasi memediasi pengaruh internalisasi budaya organisasi terhadap kapabilitas knowledge sharing sehingga diperoleh alur: internalisasi budaya organisasi mempengaruhi penggunaan teknologi informasi yang selanjutnya penggunaan teknologi informasi juga signifikan mempengaruhi kapabilitas knowledge sharing pegawai. Mediasi yang 
terjadi adalah mediasi parsial karena setelah memasukkan nilai $\mathrm{Z}$ (variabel intervening), koefisien regresi $\mathrm{X}$ terhadap $\mathrm{Y}$ menurun tetapi tidak sama dengan nol.

Berbeda dengan temuan dari uji pengaruh budaya organisasi terhadap kapabilitas knowledge sharing melalui penggunaan teknologi informasi, uji hipotesis terakhir dalam penelitian ini ternyata menunjukkan angka yang tidak signifikan sehingga $\mathrm{H}_{0}$ ditolak dan $\mathrm{H}_{1}$ diterima. Artinya, variabel penggunaan teknologi informasi tidak memediasi pengaruh struktur organisasi fungsional terhadap kapabilitas knowledge sharing. Temuan ini juga mempertegas prinsip Baron \& Kenny dalam Supriyono (2004) yang menyebutkan bahwa suatu variabel berfungsi sebagai pemediasi atau variabel intervening jika: (1) variabel bebas (X) secara signifikan berhubungan dan mempengaruhi variabel intervening; (2) variabel intervening secara signifikan berhubungan dan mempengaruhi variabel terikat (Y), dan (3) pengaruh antara variabel bebas dengan variabel terikat menurun setelah dikontrol dengan variabel intervening.

\section{PENUTUP}

Berdasarkan pengolahan dan analisis data untuk menguji pengaruh faktor- faktor organisasional dan teknologikal terhadap kapabilitas knowledge sharing pegawai di PT. PLN (Persero) area Palembang, benang merah yang diperoleh untuk menjawab rumusan masalah yaitu: Pertama, Internalisasi budaya organisasi secara signifikan mempengaruhi kapabilitas knowledge sharing pegawai PT. PLN (Persero) Area Palembang. Hal ini berarti organisasi dengan kejelasan visi yang baik, tingkat kepercayaan serta hubungan antar pegawai yang tinggi turut mendorong peningkatan kapabilitas pegawai untuk membagikan (donating) dan menyerap (collecting) pengetahuan dari rekan kerja satu departemen maupun departemen lainnya. Kedua, Struktur organisasi fungsional tidak signifikan berpengaruh terhadap kapabilitas knowledge sharing pegawai PT. PLN (Persero) Area Palembang. Organisasi dengan tingkat desentralisasi dan formalisasi yang tinggi tidak berpengaruh terhadap kapabilitas knowledge sharing pegawai, akan tetapi penerapan reward berbasis kinerja berpengaruh signifikan terhadap kapabilitas knowledge sharing pegawai. Ketiga, Pengaruh internalisasi budaya organisasi terhadap kapabilitas knowledge sharing pegawai PT. PLN (Persero) Area Palembang dimediasi secara parsial oleh variabel penggunaan teknologi informasi, artinya budaya organisasi berpengaruh terhadap penggunaan IT selanjutnya penggunaan IT berpengaruh terhadap kapabilitas knowledge sharing. Keempat, Penggunaan teknologi informasi tidak memediasi pengaruh struktur organisasi fungsional terhadap kapabilitas knowledge sharing pegawai di PT. PLN (Persero) Area Palembang.

\section{DAFTAR PUSTAKA}

Baek, Jong-Deuk. (2007). The Effect of Individual,Organizational \& Health Care System Factors on Physicians' Information Technology Use, Disertation, South Carolina: University of South Carolina.

Bashorat et al (2012). Understanding the Antecedents of Knowledge Sharing: An Organizational Justice Perspective. University of North Texas: USA.

Borins, S. (2014), The Persistence of Innovation in Government. Washington D.C: Brookings Institution Press with Ash Center for Democratic Governance and Innovation.

Buckley, P.J. and Casson, M.C (1976). The Future of the Multinational Enterprise, London: Macmillan.

Budihardjo, Andreas. (2016). Knowledge Management: Efektif Berinovasi Meraih Sukses, Jakarta: Prasetya Mulya Publishing.

Cohen, Don and Laurence Pruskak. (2001). In Good Company: How Social Capital Makes Organization Work. Boston: Harvard Business School Press.

Cooper, Donald R. Dan Schindler, Pamela S. (2014). Bussiness Research Method, 12th edition. McGraw-Hill International Edition.

Creswell, John W. (2010). Research Design: Pendekatan Kualitatif, Kuantitatif dan Mixed, Yogyakarta: Pustaka Pelajar. 
Creswell, J.W., \& Plano Clark , V.L. (2007). Designing and Conducting Mixed Method Research. Thousand Oak, CA: SAGE.

Dalkir.K. 2005. Knowledge Management in Theory and Practice. Oxford, UK: Elsevier Butterworth- Heinemann.

Davila, T., Epstein, M.J and Shelton, R. (2006). Making Innovation Work: How to Manage it, Measure it, and Profit from it, Pearson Education, Upper Saddle River, NJ.

Dwimadyasari, Vira \& Susanty, Ade I. (2015). Pengaruh Faktor Individu, Organisasi \& Teknologi terhadap Knowledge Sharing, E-Proceeding of Management: Vol. 2:1, 23-29

Eid, M. \& Al- Jabri. (2016). Social Networking, Knowledge Sharing and Student Learning: The Case of University Students, Computers and Education, 99: pp. 14-27.

Frappaolo, C. (2006). Knowledge Management. Chichester: West Sussex: Capstone Publishing Ltd.

Ismail, Mohd bahari dan Zawiyah, M. Yusof. (2008) Factors Affecting Knowledge Sharing in Public Organization in Malaysia, in Knowledge management International Conference and Exhibition,

Kusumadmo, E. (2013). Manajemen StrategikPengetahuan. Yogyakarta: Cahaya Atma Pustaka.

Maksum, Ali. (2012). Metode penelitian. Surabaya: Unesa University Press.

Marshal, Catherine dan Rossman, Gretchen B (1995). Designing Qualitative Research. California: Sage Publication,.Inc.

Marquardt, Michael J. 2002. Building the Learning Organization. Palo Alto, CA: Davies- Black Publishing.

North, Klaus \& Gita Kumta. (2014). Knowledge Management: Value Creation Through Organizational
Learning. London: Springer International Publishing.

Nurmandi, Achmad. (2016). Implementasi Knowledge Management pada Organisasi Publik, Yogyakarta: Sinergi Publishing.

Pandey, Krishna Nath. 2014. "Knowledge Management Processes : A Case Study of NTPC and POWERGRID." 2(i): 133-49.

Putra, Nusa dan Hendarman. (2013). Metode Riset Campur Sari, Jakarta: PT. Indeks.

Raharso, Sri \& Tjahjawati, Sri Surjani. (2016). Organisasi Berbasis Pengetahuan Melalui Knowledge Sharing, Bandung: Alfabeta.

Sarwono, Jonathan. (2006). Metode Penelitian Kualitatif dan Kuantitatif, Yogyakarta: Graha Ilmu.

Sekaran, Uma. (2010). Research Method for Bussiness: A Skill Building Approach, New York: John Wiley and Sons, Inc.

Skyrme.D.J \& Amindon, D.M. (1997). Creating Knowledge Based Business. London: Business Intelligence, Ltd.

Sugiyono. (2006). Metode Penelitian Administrasi, Bandung: Alfabeta.

(2011). Metode Penelitian Kuantitatif Kualitatif dan $R$ \& D, Bandung: Alfabeta.

Tofler, Alfin. (1980). The Future Shok "Third Wave". New York : Bantam Book.

Von Krogh, George. (1998). Care in Knowledge Creation: California Management Review. 40 (3): 133-153.

Wagner, Vollmar, G. \& Wagner, H.T. (2014). The Impact of Information Technology on Knowledge Creation. Journal of Enterprise Information Management, 27 (1), pp.31-44.

Wiig, K.M. (1999). Introducing Knowledge Management into the Enterprise. dalam Liebowitz, J. Ed., Knowledge 
Management Handbook, Boca Raton CRC Press,p.III-7 19.

Zamroni, Pengantar Pengembangan Teori Sosial,Yogyakarta: PT Tiara Wacana , 1992.

Alavi, M., \& Leidner, D.E. (2001). Knowledge Management and Knowledge Management System: Conceptual Foundationand Research Issues. MIS Quarterly, Vol 25 (1), pp.107-136.

Badaracco, J.L., Jr.(1991). Alliances Speed Knowledge Transfer, Planning Review, Vol 19 (2), pp.10-16.

Bock, G. \& Kim, Y. (2002). Breaking the Myths of Rewards, Information Resource Management Journal, Vol 15 (2), pp. 14-21.

Buckley, Peter and Carter, Martin J. (2003), Governing Knowledge Sharing in Multinational Enterprises, Management International Review, Vol 43 (3) pp. 725.

Calanton , R.J. Cavusgil, S.T.and Zhao, Y.(2002), Learning orientation, firm Innovation Capability and Firm Performance, Industrial Marketing Management, Vol 31 (6), pp. 515-524.

Claver- Cortes, Zaragoya- Saez and PertusaOrtega. (2007), Organizational Structure Features Supporting Knowledge Management Process, Journal of Knowledge Management, Vol 11 (4), pp 45- 57.

Dewah, Peterson \& Mutula, Stephen M. 2016. Knowledge Retention Strategies in Public Sector Organizations : Current Status in Sub-Saharan Africa. Information development, Vol 32(3): pp. 362-76.

Dwimadyasari, Vira \& Susanty, Ade I. (2015). Pengaruh Faktor Individu, Organisasi \& Teknologi terhadap Knowledge Sharing, E-Proceeding of Management: Vol. 2:1, 23-29.

Gold, A., Malhotra, A., A. Segars. (2001).
Knowledge Management: An Organizational Capabilities Perspective, Journal of Management Information System. 18 (1): 185-214.

Hansen, M.T. (1999). The Search-Transfer Problem: The Role of Weak Ties in Sharing Knowledge Across Organization Subunits, Administreative Science Quarterly, Vol 44 (1), pp. 82111.

Hoof, Bart van den \& Ridder, Jan A. (2014). Knowledge Sharing in Context: The Influence of Organizational Commitment, Communication Climate and CMC Use on Knowledge Sahring, Journal of Knowledge Management, Vol. 8 (6), pp. 117-130.

Ipe, Minu (2003). Knowledge Sharing in Organization, Human resource Development Review, Vol 2, No 4, pp. 337-359.

Lowendahl, B.R.,Revang, O. \& Fosstenlokken, S.M. (2001). Knowledge and Value Creation in Professional Service Firm: A Framework for Analysis, Human Relation, Vol 54(7), pp. 911-931.

Magni, Massimo, Corey M. Angst dan Ritu Agarwal. (2012). Everybody Needs Somebody: The Influence of Team Network Structure on Information Technology Use, Journal of Management Information System, Vol 29: 3, pp. 9-24.

McDermott, R. \& O'Dell, C. (2001). Overcoming Cultural Barriers to Sharing Knowledge, Journal of Knowledge Management, Vol 5 (1), pp. 76-85.

Nahapiet, J. dan Ghoshal, S. (1998), Social Capital, Intellectual Capital and the Organizational Advantage, Academy of Management Review, Vol 23 (2), pp. 242- 266.

Noor, Noorazah Md dan Salim, Juhana. (2011). Factors Influencing Employee Knowledge Sharing Capabilities in Electronic Government Agencies in Malaysia, International Journal of 
Computer Science Issues, Vol. 8 (2), pp. 106-114.

Okyere-Kwakye, E. \& Nor, K.M. (2011). Individual factors and Knowledge Sharing. American Journal of Economics and Business Administration, Vol 3 (1), pp.66-72.

Osterloch, M., \& Frey, B. (2000). Motivation, Knowledge Transfer, and organisational forms. Organization Science, Vol 11, pp.538-550.

Parsons, Sarah, Harry Daniels, Jill Porter dan Robertson. (2008). Resources, Staff Beliefs and Organizational Culture: Factor in the Use of Information and Communication Technology fo Adults with Intellectual Disabilities, Journal of Applied Research in Intellectual Disabilities, Vol 21, pp. 19-33.

S. Vargo and Lusch, (2004), Evolving to a New Dominant Logic for Marketing. Journal of Marketing, Vol 68 (January), p.1-17.

Saenz, Josune, Nekane Aramburu \& Olga Rivera. (2009). Knowledge Sharing and Innovation Performance, Journal of Intellectual Capital, Vol 10 (1), 22-36.

Sanchez, J.H., Collado-Ruiz D. \& Cebrian Tarrason D. (2013). Knowledge Creating and Sharing: Corporate Culture Framework. Procedia-Social and Behavioral Science. Vol 5 (4). Pp. 311321.

Scarbrough, H. (2003). Knowledge Management, HRM and Innovation Process, International Journal of manpower, Vol 24 (5), pp.501-516.

Steiger et al. (2014). An Examination of the Influence of Organizational Structure Types and Management Levels on Knowledge Management Practices in Organization, International Journal of Business and Management, Vol 9 (6); pp. 43- 57.

Storey, Chris, and Kenneth B Kahn. (2010).
The Role of Knowledge Management Strategies and Task Knowledge in Stimulating Service Innovation. Journal of Service Research,Vol 13 (4) pp. 397410.

Supriyono., R.A. (2004). Pengaruh Variabel Intervening Kecukupan Anggaran dan Komitmen Organisasi terhadap hubungan antara Partisipasi Anggaran dan Kinerja Manajerial, Jurnal ekonomi dan Bisnis Indonesia. Vol. 19. No 3, pp 282- 298.

Raharso, Sri. 2011. Pekerja Pengetahuan (Knowledge Worker): Konsepsi dan Tantangan pengelolaan, Jurnal Manajemen Usahawan Indonesia, Vol 40 (1),hlm. 58-74.

Razmerita, Kirchner dan Nielsen. (2016). What Factors Influence Knowledge Sahring in Organization? A Social Dilemma Perspective of Social Media Communication, Journal of Knowledge Management, Vol 20 (6). Pp.1225-1246.

Vera-munoz, S.C., Ho, J.L. \& Chow, C.W. (2006). Enhanching Knowledge Sharing in Public Accounting Firms, Accounting Horizons, Vol 20, pp. 133-155.

Raharso, Sri. 2011. Pekerja Pengetahuan (Knowledge Worker): Konsepsi dan Tantangan pengelolaan, Jurnal Manajemen Usahawan Indonesia, Vol 40 (1),hlm. 58-74.

Razmerita, Kirchner dan Nielsen. (2016). What Factors Influence Knowledge Sahring in Organization? A Social Dilemma Perspective of Social Media Communication, Journal of Knowledge Management, Vol 20 (6). Pp.1225-1246.

Vera-munoz, S.C., Ho, J.L. \& Chow, C.W. (2006). Enhanching Knowledge Sharing in Public Accounting Firms, Accounting Horizons, Vol 20, pp. 133-155 